\title{
Dichotic listening in schizotypal personality disorder: Evidence for gender and laterality effects
}

\section{Citation}

Voglmaier, Martina M., Larry J. Seidman, Margaret A. Niznikiewicz, Anita Madan, Chandlee C. Dickey, Martha E. Shenton, and Robert W. McCarley. 2009. Dichotic Listening in Schizotypal Personality Disorder: Evidence for Gender and Laterality Effects. Schizophrenia Research 115, no. 2-3: 290-292. doi:10.1016/j.schres.2009.04.028.

\section{Published Version}

doi:10.1016/j.schres.2009.04.028

\section{Permanent link}

http://nrs.harvard.edu/urn-3:HUL.InstRepos:28549217

\section{Terms of Use}

This article was downloaded from Harvard University's DASH repository, and is made available under the terms and conditions applicable to Other Posted Material, as set forth at http:// nrs.harvard.edu/urn-3:HUL.InstRepos:dash.current.terms-of-use\#LAA

\section{Share Your Story}

The Harvard community has made this article openly available.

Please share how this access benefits you. Submit a story.

\section{Accessibility}




\title{
Dichotic Listening in Schizotypal Personality Disorder: Evidence for Gender and Laterality Effects
}

\author{
Martina M. VogImaier, Ph.D., Larry J. Seidman, Ph.D., Margaret A. Niznikiewicz, Ph.D., \\ Anita Madan, M.A., Chandlee C. Dickey, M.D., Martha E. Shenton, Ph.D., and Robert W. \\ McCarley, M.D. \\ Harvard Medical School, Department of Psychiatry at MMHC Public Psychiatry Division of Beth \\ Israel Deaconess Medical Center, Boston, MA, Brockton/West Roxbury Veterans Affairs Medical \\ Center, Brockton, MA, and the Cambridge Health Alliance, Cambridge, MA
}

\begin{abstract}
Verbal dichotic listening performance was examined in 42 right-handed men and women with DSM-IV-defined schizotypal personality disorder (SPD) and 68 right-handed controls. As expected, both male and female control groups showed a right ear advantage on a verbal dichotic listening task. Although SPD subjects in general had lower accuracy scores than comparison subjects, only male SPD subjects showed an abnormal left ear advantage that was specifically due to deficient right ear performance. The results suggest that left hemisphere temporal lobe structures may be particularly involved in male, but not female, SPD.
\end{abstract}

\section{Keywords \\ schizotypal personality disorder; dichotic listening; perceptual asymmetry; neuropsychological dysfunction; gender differences}

\section{INTRODUCTION}

Previous studies in our laboratory have suggested a mild, general decrement in cognitive performance and presumably greater left hemisphere dysfunction based on neuropsychological test results in patients with schizotypal personality disorder (SPD) [Voglmaier et al., 1997, 2000]. More recent results suggest that a specific deficit in verbal learning, and thus left temporal lobe structures, may be a characteristic of cognitive function in males, but not females, with SPD (Voglmaier et al., 2005).

Dichotic listening tests, in which two different words or sounds are simultaneously presented to the two ears, provide a noninvasive method for assessing lateralized temporal lobe function. Dichotic listening techniques have been used to study hemispheric dominance for language in schizophrenia (SZ). Several studies have shown evidence of underactivation of left hemisphere resources for verbal processing in SZ (Wexler et al, 1991; Bruder et al, 1995), that may be related to diagnostic subtype or symptom profile (Friedman et al, 2001).

(C) 2009 Elsevier B.V. All rights reserved.

Corresponding author: Dr. Martina M. Voglmaier, Department of Psychiatry, Cambridge Health Alliance, 1493 Cambridge St., Cambridge, MA 02139. Phone: 617/665-2169, FAX: 617/665-1971, martina_voglmaier@hms.harvard.edu.

Publisher's Disclaimer: This is a PDF file of an unedited manuscript that has been accepted for publication. As a service to our customers we are providing this early version of the manuscript. The manuscript will undergo copyediting, typesetting, and review of the resulting proof before it is published in its final citable form. Please note that during the production process errors may be discovered which could affect the content, and all legal disclaimers that apply to the journal pertain. 
Similar lateralized deficits have been suggested in 'psychosis-prone' groups without formal DSM-IV diagnoses, populations thought to be at higher risk for developing SZ, with most studies suggesting left-hemisphere overactivation and/or dysfunction and slightly increased mixed- or left-hand preference (e.g., Annett and Moran, 2006, Nicholls et al, 2005).

However, these psychosis-prone individuals may differ phenomenologically from those who meet formal diagnostic criteria for SPD.

Auditory processing laterality and perceptual asymmetry have not been systematically studied in clinically-defined SPD. The purpose of the current study was to contrast auditory perceptual asymmetry by use of a verbal dichotic listening task, in men and women with schizotypal personality disorder (SPD). We used a competing sentences dichotic shadowing task to measure auditory perceptual asymmetry in male and female SPD and control subjects. Under dichotic listening conditions, left hemisphere dominance for processing words is reflected in better right ear accuracy. Based on our previous findings of left hemisphere dysfunction in SPD, we predicted that SPD subjects would show a smaller than normal or lack of right ear (left hemisphere) advantage on this task. We predicted this would be due primarily to reduced right ear performance, and that this deficit would be particularly pronounced in males.

\section{EXPERIMENTAL MATERIALS \& METHODS}

\subsection{Subjects}

Subjects were 25 right-handed men and 17 right-handed women who met DSM-IV criteria for SPD; the groups were compared to 34 right-handed male and 34 right-handed female comparison subjects, respectively, who were comparable on age, education, ethnicity, and parental socioeconomic status. Recruitment and diagnostic procedures have been described elsewhere (Voglmaier et al, 1997). Briefly, SPD subjects met full clinical diagnostic criteria based on a structured DSM-IV clinical interview (First et al, 1997). They had no lifetime history of Axis I bipolar or psychotic disorder, and no current depressive disorder. Control subjects had no lifetime history of Axis I or Axis II disorder. Audiometric tests were used to exclude those subjects with hearing loss $(>30 \mathrm{~dB}$ above normative values in either ear at $500,1000,1500$ or $2000 \mathrm{~Hz}$ ), and no ear difference greater than $15 \mathrm{~dB}$. After complete description of the study to the subjects, written informed consent was obtained. All subjects were paid for their participation in the study.

\subsection{Procedure}

Subjects were presented the Competing Sentences Task (AudiTec), which included 30 pairs of sentences, delivered dichotically. Each sentence pair begins and ends simultaneously and includes similar subject matter, e.g. Left Ear/'They say candy is bad for your teeth"; Right Ear/"I do not like to eat dinner alone". Subjects were instructed to attend selectively, or shadow, a particular ear and report the content verbatim: "Focus only on Left ear, Ignore the Right. Repeat the message you hear in the left ear." The examiner recorded the subject's response verbatim. Content was scored for each word correct, intrusions from the opposite ear, and other errors. In half of the trials, subjects were asked to attend to and report only right ear words; in the other half, subjects were asked to attend to and report only left ear words. Orientation of headphones and the initial target ear were counterbalanced across subjects to control for channel differences and ear of presentation. Auditory stimuli were presented at a comfortable level of $70 \mathrm{~dB}$ SPL.

\subsection{Data Analysis}

The percentage of correct responses was computed for right (R) and (L) ear presentations. A repeated measures ANOVA was employed, with Ear (right/left), Group (SPD/NC) and Sex 
(Male/Female) as the independent variables and Percent Correct as the dependent variable. Post hoc Tukey $\mathrm{T}$ tests were employed to examine specific differences in ear performance across groups.

\section{RESULTS}

Repeated measures ANOVA demonstrated a significant Ear X Group X Sex interaction, $\mathrm{F}(1,106)=5.419, \mathrm{p}=.022$ (see Figure 1). This was due to a significant Ear $\mathrm{X}$ Group interaction for males $(\mathrm{F}[1,57]=6.982, \mathrm{p}=.011)$ but not for females $(\mathrm{F}[1,49]=.481)$. Compared to male control subjects, male SPDs showed generally reduced accuracy as well as an abnormal left ear advantage on the Competing Sentences task. Post hoc Tukey T tests indicated that this was due to significantly poorer right ear performance $(\mathrm{p}<.05)$.

There was a significant main effect of Group $(F[1,106]=9.859, p=002$, with SPD subjects having generally lower accuracy scores than control subjects. This was evident primarily in males. Post-hoc analyses indicated no significant difference in performance of female SPDs and female control subjects, who showed a right ear advantage on this task.

\section{DISCUSSION}

The results suggest that left temporal lobe dysfunction may be a specific characteristic of men, but not women, with SPD. In the current study, both male and female control subjects showed a right ear advantage on a verbal dichotic shadowing test. Although SPD subjects in general had lower accuracy scores than control subjects, only male SPD subjects showed an abnormal left ear advantage on this task, and this was specifically due to deficient right ear performance.

The results are consistent with our previous findings of reduced verbal memory processing suggestive of left-temporal lobe dysfunction in men, but not women, with SPD (Voglmaier et al., 2005). It is noteworthy that among male SPDs, current dichotic listening performance correlated significantly with performance on a measure of verbal short-term retention (trigram recall, $\mathrm{r}(25)=-.40, \mathrm{p}<.05)$, but was not related to performance on other measures of verbal processing, including vocabulary, verbal fluency or word-list learning. This is consistent with our previous work suggesting a specific deficit in the early processing stages of verbal learning in SPD (Voglmaier, et al., 2000).

To our knowledge, this is the first study to examine auditory processing laterality in DSMIV defined SPD. These and other neuropsychological test results from our laboratory have been consistent with hypotheses of disinhibition of the semantic language network in schizophrenia-spectrum disorders (e.g. McCarley et al 1999) and suggest that similar hypotheses may be true in DSM-IV defined SPD (Voglmaier et al, 1997, 2000). Such hypotheses purport that the response-bias established by semantic content may be inefficiently selective in schizophrenia, resulting in a state of "cognitive disinhibition" that may underlie loose associations, magical thinking and thought disorder.

The neuropsychology of SPD may be understood within the context of hypotheses that schizophrenia involves deficits in a highly interconnected neural system involving prefrontal and temporal lobe structures. Within such a framework, cognitive deficits could reflect dysfunction at any one or more points within the system and vary accordingly. Further study of neuropsychological function in clinically-defined SPD is important for advancing our understanding of the cognitive and clinical features of SPD and its relationship to SZ. 


\section{References}

Annett M, Moran P. Schizotypy is increased in mixed-handers, especially right-handed writers who use the left hand for primary actions. Schizophr Res. 2006 Jan 31; 81(2-3):239-46. [PubMed: 16298105]

Bruder G, Rabinowicz E, Towey J, Brown A, Kaufmann CA, Amador X, Malaspina D, Gorman JM. Smaller right ear (left hemisphere) advantage for dichotic fused words in patients with schizophrenia. American Journal of Psychiatry. 1995; 152:932-935. [PubMed: 7755128]

Bruder GE, Wexler BE, Sage MM, Gil RB, Gorman JM. Verbal memory in schizophrenia: additional evidence of subtypes having different cognitive deficits. Schizophrenia Research. 2004; 68(2-3): 137-147. [PubMed: 15099598]

First, MB.; Gibbon, M.; Spitzer, RL.; Gibbon, M.; Williams, JBW.; Benjamin, LS. Structured Clinical Interview for DSM-IV Axis II Personality Disorders (SCID-II). Washington, DC: American Psychiatric Press; 1997.

Friedman MS, Bruder GE, Nestor PG, Stuart BK, Amador XF, Gorman JM. Perceptual asymmetries in schizophrenia: subtype differences in left hemisphere dominance for dichotic fused words. Am J Psychiatry. 2001; 158(9):1437-1440. [PubMed: 11532728]

Kendler KS, McGuire M, Gruenberg AM, O’Hare A, Spellman M, Walsh D. The Roscommon family study I. Methods, diagnosis of probands and risk of schizophrenia in relatives. Arch Gen Psychiatry. 1993; 50:527-540. [PubMed: 8317947]

McCarley RW, Niznikiewicz MA, Salisbury DF, Nestor PG, O’Donnell BF, Hirayasu Y, Grunze H, Greene RW, Shenton ME. Cognitive dysfunction in schizophrenia: unifying basic research and clinical aspects. European Arch Psychiatry Clin Neurosci. 1999; 249(Suppl. IV):69-82. [PubMed: 10654112]

Nicholls ME, Orr CA, Lindell AK. Magical ideation and its relation to lateral preference. Laterality. 2005 Nov; 10(6):503-15. [PubMed: 16298883]

Voglmaier MM, Seidman LJ, Salisbury D, McCarley RW. Neuropsychological dysfunction in schizotypal personality disorder: A profile analysis. Biol Psychiatry. 1997; 41:530-540. [PubMed: 9046985]

Voglmaier MM, Seidman LJ, Ninikiewicz MA, Dickey CC, Shenton ME, McCarley RW. Verbal and nonverbal neuropsychological test performance in subjects with schizotypal personality disorder. Am J Psychiatry. 2000; 157:787-793. [PubMed: 10784473]

Voglmaier MM, Seidman LJ, Ninikiewicz MA, Dickey CC, Shenton ME, McCarley RW. A comparative profile analysis of neuropsychological test performance in men and women with schizotypal personality disorder. Schiz Research. 2005; 74(1):43-49.

Wexler BE, Giller EL Jr, Southwick S. Cerebral laterality, symptoms and diagnosis in psychotic patients. Biological Psychiatry. 1991; 29:103-116. [PubMed: 1995082] 


\section{Dichotic Competing Sentences}

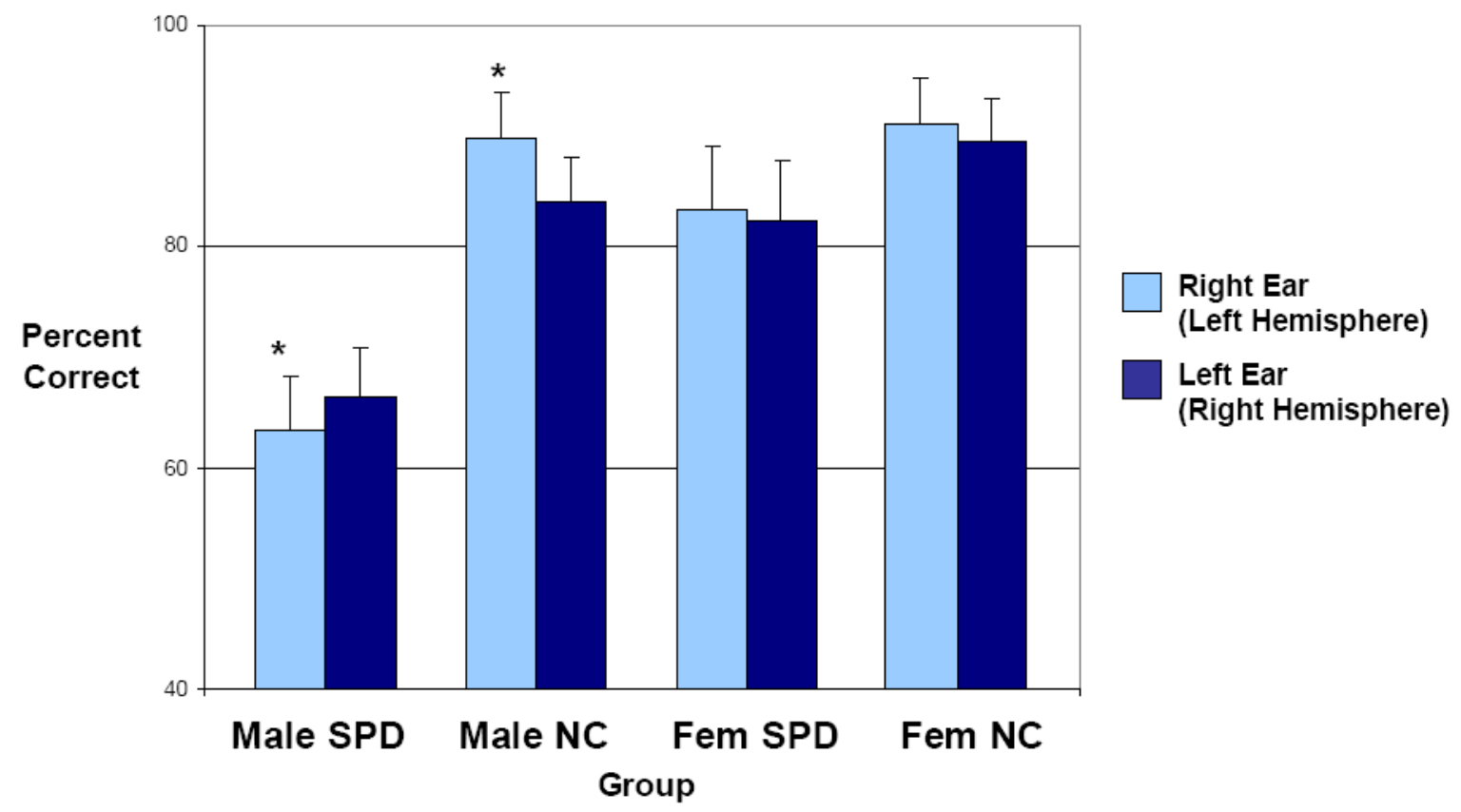

Figure 1.

Dichotic Competing Sentences Task Performance in Male and Female SPD and Comparison Groups.

Mean percent correct ear performance as a function of diagnosis and gender. Standard error bars are indicated. Note that male SPD subjects are the only group to show a left ear (right hemisphere) advantage. This was due to a significant decrement in right ear performance. $*=$ significant difference, $\mathrm{p}<.05$ 